\title{
High strain rate and high temperature response of two armour steels: Experimental testing and constitutive modelling
}

\author{
Brodie McDonald ${ }^{1,2,3^{*}}$, Huon Bornstein ${ }^{3}$, Ali Ameri ${ }^{4}$, Juan P. Escobedo-Diaz ${ }^{4}$, Adrian C. Orifici ${ }^{1}$ \\ ${ }^{1}$ School of Engineering, RMIT University, PO Box 71, Bundoora, Victoria 3083, Australia \\ ${ }^{2}$ Defence Materials Technology Centre (DMTC), 24 Wakefield St, Hawthorn, Victoria 3122, Australia \\ ${ }^{3}$ Defence Science and Technology Group (DST-G), 506 Lorimer St, Fishermans Bend, Victoria 3207, Australia \\ ${ }^{4}$ School of Engineering and Information Technology, University of New South Wales, Northcott Dr, Campbell, ACT 2612, Australia
}

\begin{abstract}
Under ballistic impact or blast loading, the high strain rate and high temperature behaviour of armour steels is key to their response to a given threat. This experimental and numerical investigation examines the tensile response of a class 4a improved rolled homogenous armour steel (IRHA) and a high hardness armour steel (HHA). Cylindrical tensile specimens were tested at a range of strain rates from 0.001 $\mathrm{s}^{-1}$ to $2700 \mathrm{~s}^{-1}$. Quasi-static, elevated temperature tests were performed from room temperature up to $300^{\circ} \mathrm{C}$. While the HHA is strain rate insensitive, the IRHA displays a significant increase in strength across the range of loading rates reducing the ultimate strength difference between the materials from $19 \%$ at $0.001 \mathrm{~s}^{-1}$ to $4.6 \%$ at $2700 \mathrm{~s}^{-1}$. An inverse numerical modelling approach for constitutive model calibration is presented, which accurately captured the dynamic material behaviour. The modified Johnson-Cook strength and Cockcroft-Latham (C-L) fracture models were capable of predicting the ballistic limit of each material to within $5 \%$ of the experimental result and to within $10 \%$ for deformation under blast loading. The blast rupture threshold of both materials was significantly over-estimated by the C-L model suggesting stress state or strain rate effects may be reducing the ductility of armour steel under localised blast loading.
\end{abstract}

\section{Introduction}

In protective structures armour steels are utilised to defeat various blast and ballistic threats. Under the extreme loading conditions caused by these dynamic events, the material can experience high strain rate plastic deformation and elevated temperatures caused by adiabatic heating. Numerous grades of armour steel are defined in defence standards [1-3] with mechanical performance and metallurgy optimised for protection against specific threats whilst maintaining adequate engineering properties. Class $4 \mathrm{a}$ rolled homogenous armour [1], generally referred to as improved rolled homogenous armour (IRHA) [4] is a modern grade of armour steel optimised for combined strength and toughness with a Brinell hardness between 420 and 470 . High hardness armour (HHA) steel [2] is optimised for ballistic protection with a Brinell hardness between 477 and 534 and lower Charpy fracture toughness requirements than the IRHA.

Ballistic testing by Showalter [5] highlighted the comparable performance of an IRHA and a HHA grade in defeating armour piecing ammunition. The performance of monolithic steel armour against this threat class has been observed to generally scale with material hardness [6]. While no specific explanation was given for the similar performance, Showalter commented that with negligible differences in ballistic protection, higher toughness and improved weldability, the IRHA grade would be better choice of armour material than the traditional HHA in a structural

\footnotetext{
* Corresponding author: s3333246@student.rmit.edu.au
}

application[5]. Numerical analysis of both grades of steel against similar ballistic threats can give insight into each materials response and be used to explore the source of their comparable performance.

A comparison of four grades of armour steel under localised blast loading was presented by McDonald [7] and showed that the normalised deformation resistance of an IRHA grade exceeded that of two higher yield strength RHA grades and approached that provided by HHA, regardless of the $20 \%$ higher tensile yield strength. While the strain hardening of the IRHA material was highlighted as a major contributor to its high deformation resistance [7], the influence of strain rate and temperature on the different armour steels protective capacity was not described.

This paper evaluates the mechanical response of an IRHA and a HHA grade of steel under a range of tensile loading conditions, which include high strain rates and temperatures. The experimental data and an inverse modelling approach is used to generate Modified Johnson-Cook strength and Cockcroft-Latham fracture model constants for each steel. The resulting constitutive models are implemented in numerical simulations of ballistic impact and blast loading to explore the comparative performance of each steel.

\section{Material Characterisation}

The specimen geometries used to assess the IRHA and HHA steels are shown in Fig. 1. Triplicate tests were 
performed for each sample type to gauge repeatability of the results and homogeneity of mechanical properties throughout the parent material. All samples were taken along the rolling direction of the plate. The specimens (Fig. 1a) were tested under tensile loading at a constant cross-head velocity of $0.045 \mathrm{~mm} / \mathrm{s}$ until fracture corresponding to $0.001 \mathrm{~s}^{-1}$. Elongation was measured by a non-contact extensometer about a $45 \mathrm{~mm}$ gauge length defined at the beginning of the test.

\subsection{Room Temperature Tests}

Engineering stress-strain curves for the IRHA and HHA steel are presented in Fig. 2. Both materials show a significant work hardening capacity at low strains and large post-necking elongation. The ultimate tensile strength (UTS) of HHA is 19\% higher than the IRHA while elongation to fracture is marginally lower $(-3 \%)$

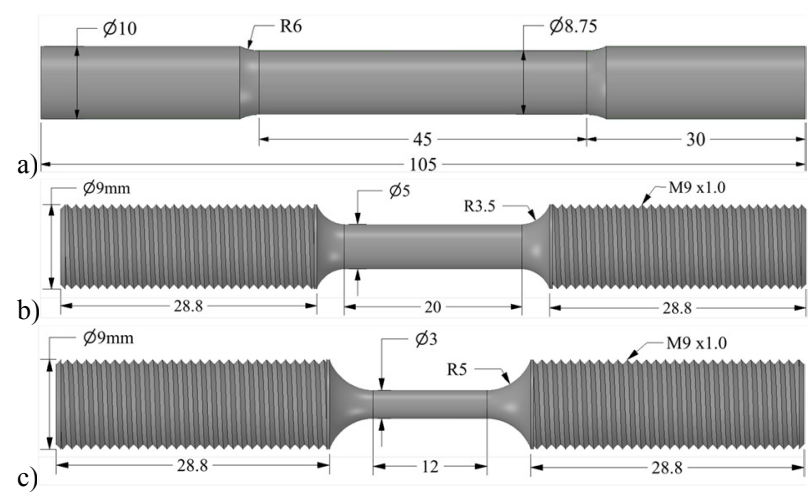

Fig. 1. Samples for mechanical testing. a) Quasi-static b) High temperature c) High strain rate.

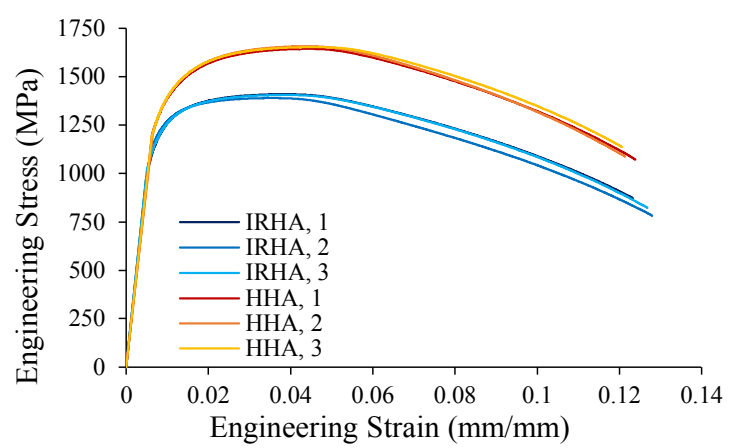

Fig. 2. Quasi-static, room temperature stress-strain results.

\subsection{Elevated Temperature Tests}

The effect of elevated temperatures on the flow properties of each steel was characterised by a series of quasi-static tensile experiments performed on cylindrical specimens (Fig. 1b) in a universal testing machine equipped with an electric furnace. The specimens were brought to the required temperature and held for 25 to 35 minutes before testing to ensure thermal equilibrium had been reached throughout the material. Fig. 3 shows the engineering stress-strain response of each material at room temperature $\left(25^{\circ} \mathrm{C}\right), 150^{\circ} \mathrm{C}$ and $300^{\circ} \mathrm{C}$.

Both materials show a distinct blue-brittle effect at the $150^{\circ} \mathrm{C}$ test condition where-by the strength is higher compared to room temperature and material ductility is lower than at the other conditions. This effect has been observed in other high strength steel grades [8], but is not generally accounted for in constitutive modelling where the flow stress is typically monotonically reduced with temperature.

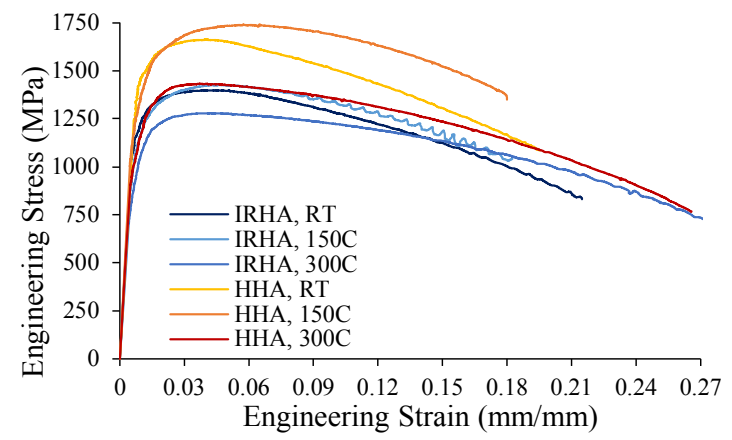

Fig. 3. Effect of elevated temperatures on the stress-strain behaviour of armour materials.

\subsection{Elevated Strain Rate Tests}

To investigate the tensile plasticity and fracture behaviour of the candidate materials at elevated strain rates, a series of experiments were performed at the UNSW impact dynamics laboratory using cylindrical specimens of each material with dimensions shown in Fig. 1c. Intermediate strain rate tests $\left(0.1 \mathrm{~s}^{-1}\right)$ were completed on the same universal test machine used in Section 2.2 while a tensile split Hopkinson tensile bar (T-SHTB) was used to test at strain rates above $600 \mathrm{~s}^{-1}$. See Ameri [9] for full details of the T-SHTB test setup. Engineering stress-strain curves for the candidate materials at four strain rates are provided in Fig. 4 and Fig. 5. Oscillations can be seen in the IRHA signal at a strain rate of $2700 \mathrm{~s}^{-1}$, which were caused by stress reflections from a sample adapter on the transmitted bar. Direct attachment of the samples was used for the HHA material, and this significantly reduced the signal noise.

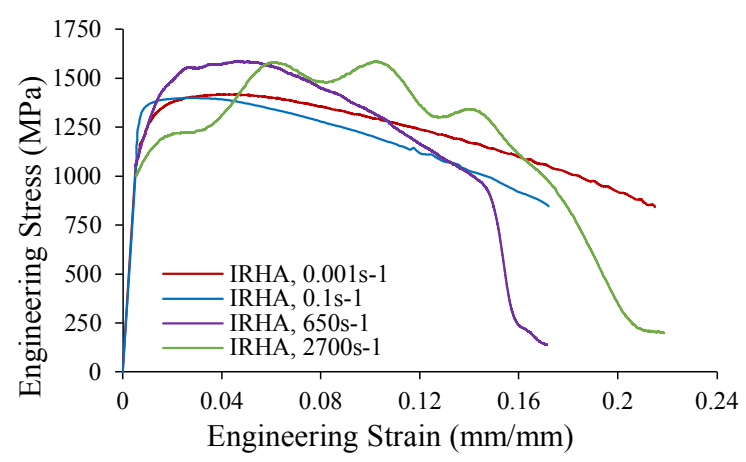

Fig. 4. Effect of elevated strain rate on the stress-strain behaviour of IRHA material.

While the HHA material appears to be strain rate insensitive, the IRHA shows a significant increase in ultimate strength at high strain rates. At the highest loading rate, the strength of the IRHA material approaches that of the HHA. The effect of strain rate on the ductility for both steels is shown in Fig. 6. It was calculated by measuring the initial and fractured diameter of the specimens using a microscope. Both 
materials display a slight decrease in ductility as the strain rate increases. For a strain rate of $2700 \mathrm{~s}^{-1}$, the reduction is $2.5 \%$ for IRHA and $6.5 \%$ for HHA.

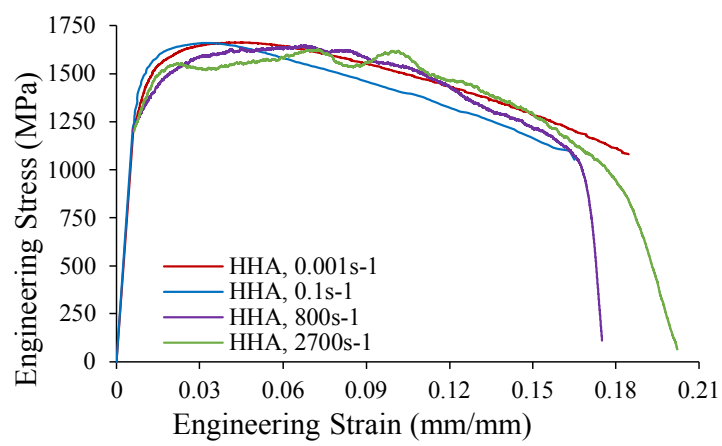

Fig. 5. Effect of elevated strain rates on the stress-strain behaviour of HHA material.

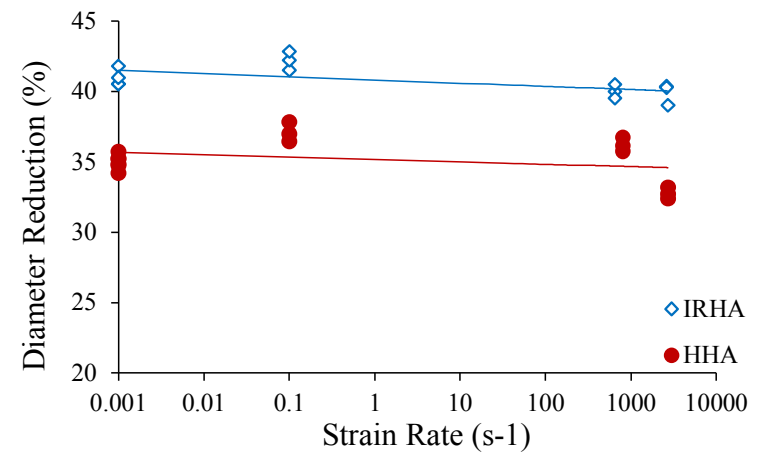

Fig. 6. Effect of strain rate on ductility for armour materials.

\section{Constitutive Modelling}

The modified Johnson-Cook (MJC) plasticity model with Voce hardening and a two-stage strain rate hardening relationship is given by Equation 1[8].

$$
\begin{gathered}
\sigma_{0}=\left\{A+B \varepsilon_{p l}^{n}+\sum_{i=1}^{2} Q_{i}\left[1-\exp \left(-C_{i} \varepsilon_{p l}\right)\right]\right\} \\
\sum_{i=1}^{2}\left[1+\frac{\dot{\varepsilon}}{\dot{\varepsilon}_{0, i}}\right]^{C_{i}}\left[1-\left(\frac{T-T_{0}}{T_{M}-T_{0}}\right)^{M}\right]
\end{gathered}
$$

where, $A, B, n, Q_{i}, C_{i}, c_{i}$ and $M$ are material constants, $\dot{\varepsilon}_{0, i}$ are reference strain rates and $T_{0}$ and $T_{m}$ are initial and melting temperatures of the material respectively.

The two-part strain rate hardening component of Equation 1 was formulated to account for high strain rate dislocation drag on material strength. While there are other strain rate descriptions which can capture the distinct up-turn in material strength at high strain rates [10], this approach allows the independent characterisation of the two strain rate regimes via separate exponents $\left(c_{1}, c_{2}\right)$ and a threshold strain rate $\left(\dot{\varepsilon}_{0,2}\right)$, below which dislocation drag is neglected. The maximum stress (converted to true stress) and average strain rates from Fig. $\mathbf{4}$ and Fig. $\mathbf{5}$ are shown against the strain rate component to demonstrate its formulation in Fig. 7.

Fracture of the materials is modelled by the Cockcroft-Latham (C-L) criterion [11]. This simple fracture model has been used with success for modelling ballistic [12] and blast response [13] of various materials and is evaluated here-in as a starting point for the fracture modelling of these armour steels. The C-L fracture model is given in Equation 2.

$$
W=\int_{0}^{\varepsilon_{p l}}\left\langle\sigma_{1}\right\rangle d \varepsilon_{p l} \leq W_{c}, \quad\left\langle\sigma_{1}\right\rangle=\max \left(\sigma_{1}, 0\right)
$$

where $W_{c}$, is the material critical plastic work given by numerical calibration of a uniaxial tensile test to fracture.

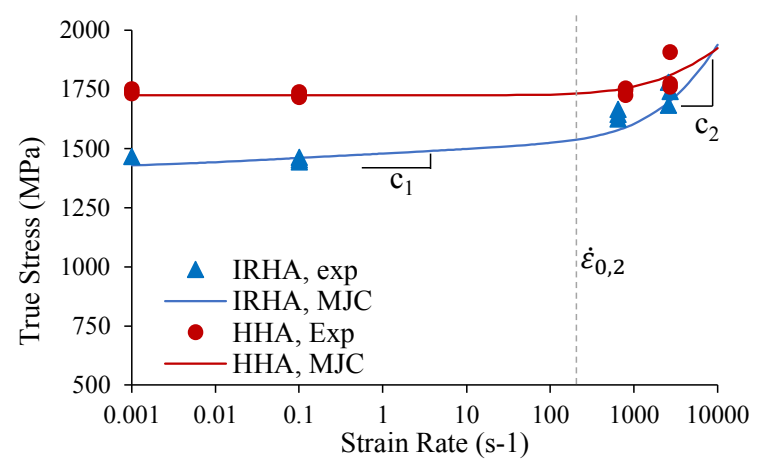

Fig. 7. Effect of strain rate on ultimate tensile strength and two-part strain rate relationship with key components labelled.

\subsection{Calibration Approach}

Inverse modelling of the mechanical tests was performed in the LS-Dyna explicit solver to calibrate each aspect of material plasticity. Given the independent, phenomenological nature of the modified Johnson-Cook strength model given in Equation 1, calibration was separated into three sequential stages, with a single aspect of the plasticity model calibrated in each stage.

A 2D axisymmetric model of each specimen type was created with an element edge length of $0.2 \mathrm{~mm}$ in the critical areas. The accuracy of the material calibration was assessed by its ability to recreate the engineering stress-strain curves for each test condition given in Section 2, a least squares method of curve comparison was used and results converged to the final values generally within 1000 iterations for section 3.2 and 100 for section 3.3 and 3.4.

\subsection{Plasticity}

Quasi-static and room temperature plasticity for each material was calibrated to the responses given in Fig. 2 by optimising the Swift and Voce hardening terms $\left(A, B, n, Q_{i}, C_{i}\right)$ in Equation 1. A prescribed velocity of $0.05 \mathrm{~mm} / \mathrm{s}$ was applied to the model and the reaction forces measured at the opposite end of the specimen. The experimental and numerical engineering stress-strain curves for each material are compared in Fig. 8. The models are shown to provide an excellent recreation of the plasticity behaviour.

\subsection{Thermal Softening}

Simulations of the elevated temperature tests were performed with the quasi-static and isothermal plasticity parameters identified in Section 3.2. The thermal softening coefficient $(M)$, was optimised for recreation of the stress-strain responses in Fig. 3. A comparison of 
the optimal numerical results and experiments are given in Figs. 9 and 10.

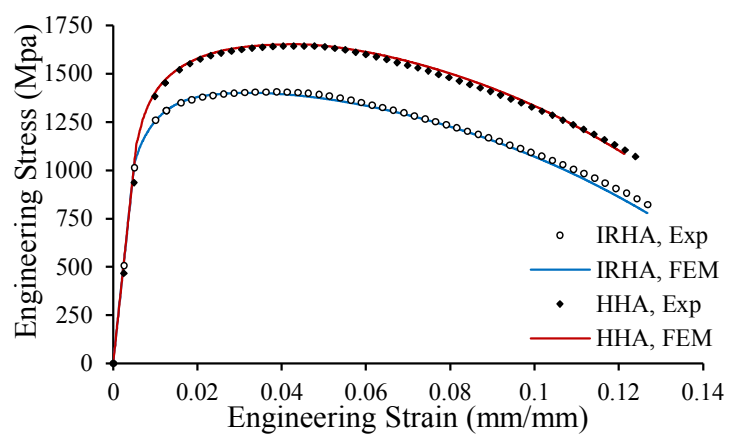

Fig. 8. Quasi-static experimental and numerical tensile response of IRHA and HHA materials.

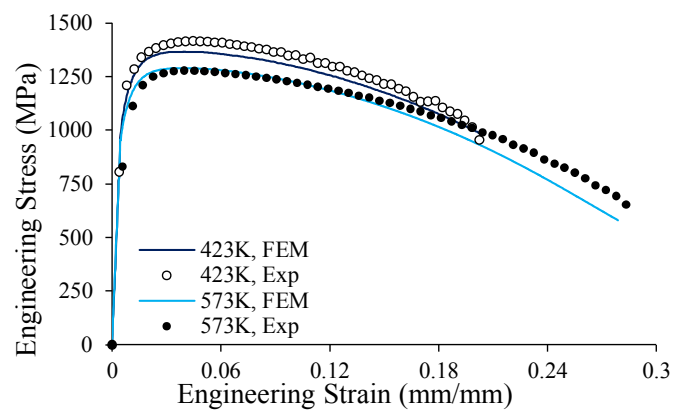

Fig. 9. Experimental and numerical response of IRHA at elevated temperatures.

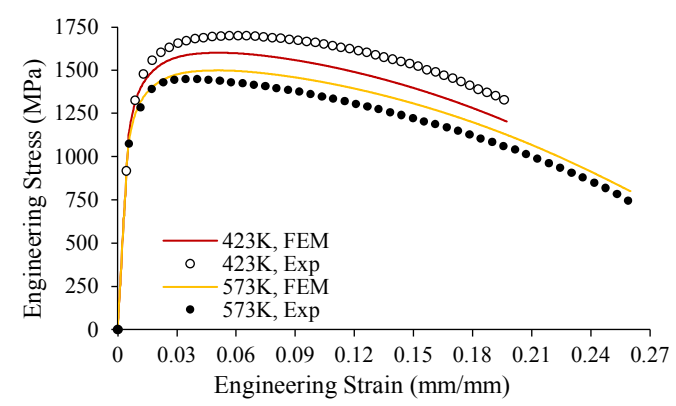

Fig. 10. Experimental and numerical response of HHA at elevated temperatures.

Both materials showed low thermal softening across the tested temperature range resulting in a high value of $\mathrm{M}$ in the constitutive model. The pronounced blue-brittle response of the HHA at $150^{\circ} \mathrm{C}$ makes calibration of the thermal softening difficult with the Johnson-Cook model. A more detailed model which can capture temperature dependant hardening such as TRUAM [14] may produce better results for materials within this range.

\subsection{Strain Rate Hardening}

Material response at elevated loading rates is dependent on the combined effects of strain rate hardening and adiabatic heating. The traditional method of calibrating strain rate hardening behaviour fails to capture the coupled thermal effects and the increase in strain rate experienced within the necking material. To accurately reproduce the conditions experienced during testing with the T-SHPB, the full apparatus was modelled. This included measuring the elastic strains from the correct positions on the incident and transmitted bars to derive the stress-strain outputs.

Using the thermal softening coefficient derived in Section $3.3(M=1.5)$ allowed accurate recreation of the material response up to the ultimate tensile strength. However, this approach significantly underestimated the magnitude of thermal softening accompanying strain localisation. Simultaneous calibration of the strain rate hardening and thermal softening behaviour using the T-SHPB simulations significantly improved the constitutive models ability to capture high strain rate behaviour.

The experimental and numerical response for each high strain rate condition is given in Figs 11 to 14, highlighting the effect of the thermal softening coefficient on the materials load carrying capability beyond strain localisation. The difference in thermal softening coefficient calibrated in Section 3.3 compared to the optimal high strain rate value highlights a change in material behaviour when subjected to isothermal elevated temperatures and plastic work heating. Given the focus on high strain rate response in the evaluation of armour materials, the thermal softening coefficient calibrated from SHTB testing will be used in Section 6 .

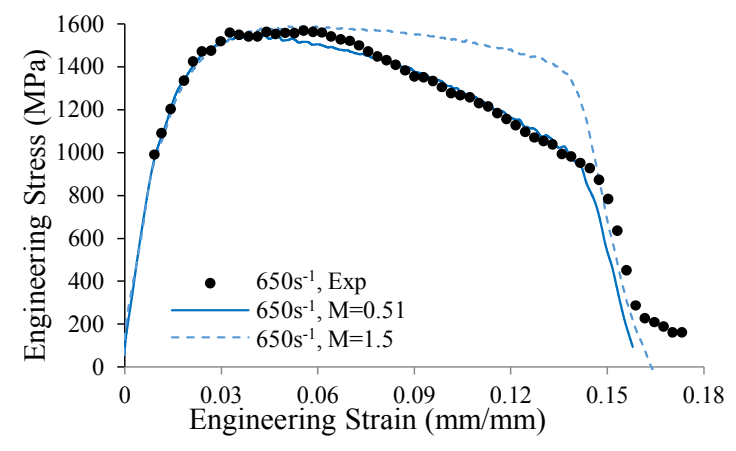

Fig. 11. Numerical response of IRHA at $650 \mathrm{~s}^{-1}$ using derived and re-calibrated thermal softening coefficient.

\subsection{Fracture}

As per the C-L model calibration process of Aune [13], the critical plastic work $W_{c}$, was extracted for each material from the numerical models used in calibration of quasi-static isothermal plasticity. The critical element was taken in the centre of the neck where plastic strain was highest. The significant cross-section reduction to failure of the IRHA results in a higher critical plastic work of $2781 \mathrm{MPa}$ than the HHA with $2356 \mathrm{MPa}$. The complete set of material parameters describing the IRHA and HHA material is given in Table 1.

\section{Protective Capacity}

With detailed insight into the strength and ductility of IRHA and HHA steel across a range of temperatures and strain rates, the constitutive models produced in Section 3 can be used to investigate the response of each material against real-world threats from ballistic and blast loading. The accuracy of the presented material characterisation approach is evaluated by comparing the 
performance of IRHA and HHA steels to the ballistic tests conducted by Showalter [5] and the blast testing conducted by McDonald [7].

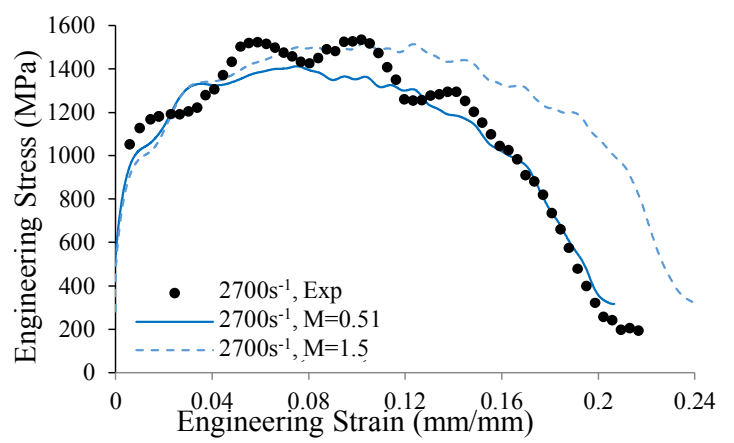

Fig. 12. Numerical response of IRHA at $2700 \mathrm{~s}^{-1}$ using derived and re-calibrated thermal softening coefficient.

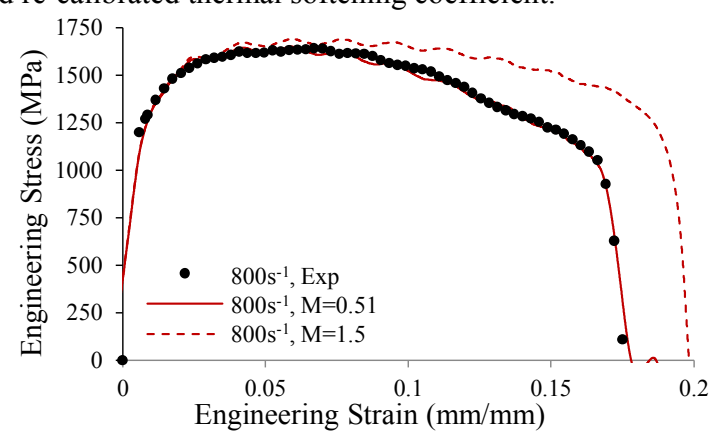

Fig. 13. Numerical response of IRHA at $800 \mathrm{~s}^{-1}$ using derived and re-calibrated thermal softening coefficient.

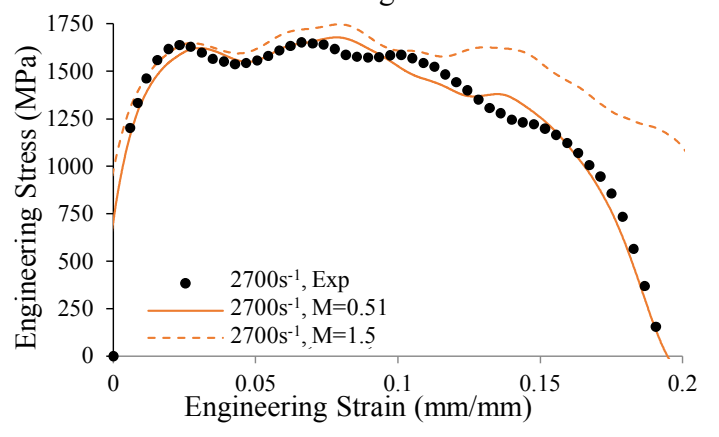

Fig. 14. Numerical response of HHA at $2700 \mathrm{~s}^{-1}$ using derived and re-calibrated thermal softening coefficient.

Table 1. Material parameters for IRHA and HHA steels.

\begin{tabular}{|c|c|c|}
\hline Material & IRHA & HHA \\
\hline$A(\mathrm{MPa})$ & 1041 & 1137 \\
\hline$B(\mathrm{MPa})$ & 374 & 420 \\
\hline$n$ & 0.418 & 0.380 \\
\hline$Q_{1}(\mathrm{MPa})$ & 253 & 159 \\
\hline$C_{1}$ & 159 & 594 \\
\hline$Q_{2}(\mathrm{MPa})$ & 71.0 & 315 \\
\hline$C_{2}$ & 427 & 95.6 \\
\hline$m$ & 0.51 & 0.80 \\
\hline$c_{1}$ & 0.015 & 0.001 \\
\hline$\dot{\varepsilon}_{0,1}\left(\mathrm{~s}^{-1}\right)$ & 0.001 & 0.001 \\
\hline$c_{2}$ & 0.025 & 0.065 \\
\hline$\dot{\varepsilon}_{0,2}\left(\mathrm{~s}^{-1}\right)$ & 3000 & 10000 \\
\hline$W_{c}(\mathrm{MPa})$ & 2781 & 2356 \\
\hline
\end{tabular}

\subsection{Ballistic Performance}

The ballistic limit of $10 \mathrm{~mm}$ Bisalloy IRHA and HHA steel against a $7.62 \mathrm{~mm}$ APM2 projectile was measured by Showalter [5] as $708 \mathrm{~ms}^{-1}$ and $702 \mathrm{~ms}^{-1}$ respectively. Utilising the APM2 projectile properties and numerical modelling approach of Borvik et al. [12], the ballistic limit of IRHA and HHA was calculated via the LambertJonas Equation [15] from seven initial velocity cases. The ballistic limit predictions for each material are compared to the experimental value in Fig. 15. Numerical predictions for both materials are within 5\% of the experiments; however, the IRHA is underpredicted while the HHA is over-predicted. While the numerical predictions are comparable to experimental results, the difference in ballistic limit between each steel is higher than that identified by Showalter [5], this may be due to differences in fracture behaviour not captured by the simplistic C-L model or changes in material behaviour at the extremely high strain rates during ballistic impacts.

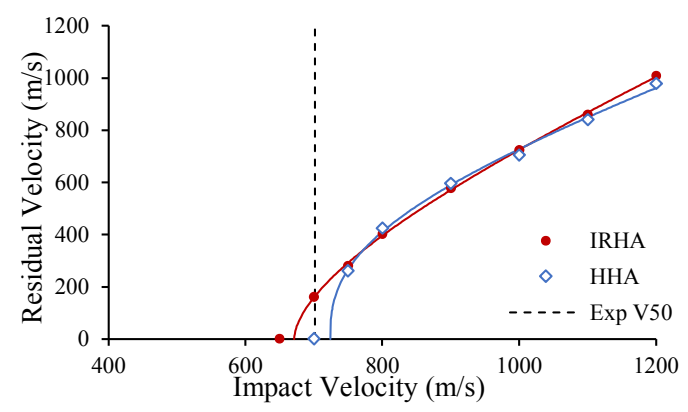

Fig. 15. Ballistic limit predictions for armour materials.

\subsection{Blast Performance}

Blast tests were conducted by McDonald et al. [7] to compare the deformation and rupture performance of a range of armour steels including IRHA and HHA. These tests provided 21 experimental conditions to evaluate capability of the current constitutive model to capture the deformation behaviour of the two materials. The target plate was modelled using 3D solid elements, while a multi-material arbitrary Lagrangian Eulerian (MM-ALE) domain was used to model the detonation and expansion of the cylindrical PE4 charge and was coupled to the target plate via a penalty-based constraint algorithm. The target plate was discretised with $0.2 \mathrm{~mm}$ elements based on the mesh size used in Section 3, and a convergence study of the loading from the explosive charge resulted in a $0.8 \mathrm{~mm}$ mesh element length for the fluid domain. The correlation between the experimental and numerical results for each test condition is provided in Fig. 16, where exact reproduction is given by the black dashed line and an error of $\pm 10 \%$ by the grey.

Following the validation of the numerical modelling approach for predicting deformation, a series of 18 additional simulations were conducted comparing the deformation and maximum plastic work of IRHA and HHA against explosive charges between $40 \mathrm{~g}$ and $140 \mathrm{~g}$ (50 mm Diameter, $25 \mathrm{~mm}$ stand-off distance, $4.0 \mathrm{~mm}$ plate thickness). To evaluate the influence of the strain rate hardening capacity of IRHA on its blast performance, simulations were repeated for the IRHA 
with the strain rate exponents $\left(c_{i}, \dot{\varepsilon}_{0, i}\right)$ of the HHA material (labelled IRHA*). Fig. 17 compares the deformation and maximum plastic work for the IRHA, IRHA* and HHA across the range of charge sizes. At lower charge sizes there is minimal difference between the IRHA and HHA. However, the strain rate insensitive IRHA* has higher levels of deformation at all loading conditions. At higher loading conditions where plastic deformation and in-turn the effects of strain hardening capacity are increased, the HHA outperforms the IRHA in terms of deformation but only by $8 \%$ for the maximum load case evaluated.

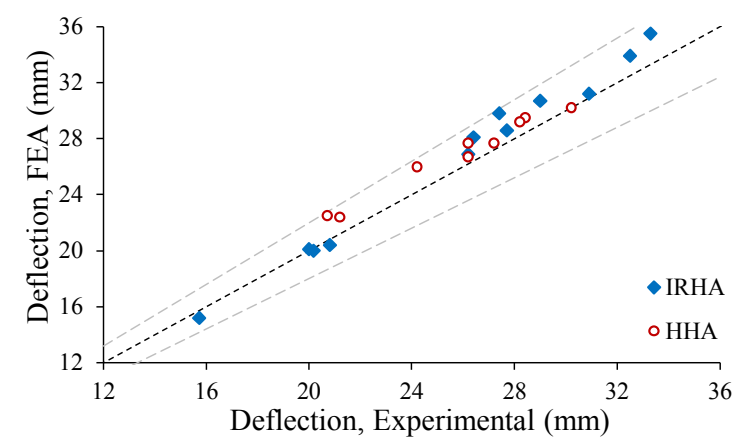

Fig. 16. Numerical and experimental correlation across a range of blast loading conditions for IRHA and HHA steel.

Experimentally, the charge mass to rupture the IRHA and HHA materials was $72.5 \mathrm{~g}$ and $60 \mathrm{~g}$ respectively [7]. However, even for the $140 \mathrm{~g}$ charge size, the maximum plastic work in the numerical simulations was approximately $60 \%$ of each materials critical value. Only the IRHA* was predicted to fracture at a charge mass of $140 \mathrm{~g}$, proceeded by significant localised necking in the plate, which was not seen experimentally.

The C-L fracture model appears to be unable to capture the failure of the current armour steels under blast loading. While the C-L model does incorporate stress triaxiality and lode angle dependence on fracture [13], the fixed locus shape and limited calibration may limit its accuracy compared to a more detailed fracture model, which can be fit to numerous characterisation tests and have independent strain rate and temperature dependence [14].

\section{Conclusions}

This experimental and numerical investigation examines the tensile response of a class $4 \mathrm{a}$ improved rolled homogenous armour (IRHA) and high hardness armour (HHA) steel across a range of loading conditions including elevated temperatures and high strain rates. While the HHA material was seen to be strain rate insensitive, the IRHA showed a significant increase in strength under dynamic loading. The material response was adequately captured by a modified Johnson-Cook strength model; however, a difference in thermal softening behaviour was seen at quasi-static and high strain rates, which should be investigated further. The constitutive models were validated against ballistic impact and blast loading experiments from literature and highlighted that the high strain rate hardening capacity of the IRHA is a key factor in its comparable performance to HHA under dynamic loading. The Cockcroft-Latham criterion was unable to accurately model fracture for the blast scenarios evaluated. Hence, further work using alternative approaches to modelling fracture are required to accurately model the fracture of armour steel across a range of blast loading conditions.

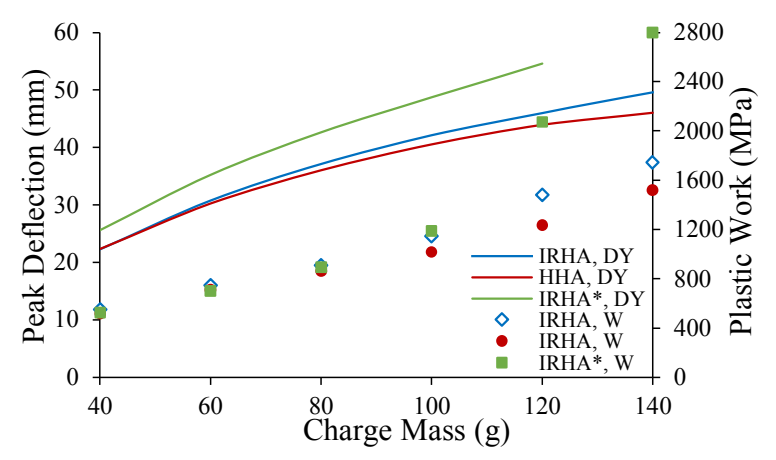

Fig. 17. Deflection (DY) and maximum plastic work (W) of IRHA and HHA under localised blast loading.

The authors acknowledge the support of the Defence Materials Technology Centre, which was established and is supported by the Australian Government's Defence Future Capability Technology Centre (DFCTC) initiative.

The authors are grateful to Mr. Tyler Bikaun for his assistance with conducting the ballistic simulations.

\section{References}

1. U.S Detail Specification. MIL-DTL-46100E (2008)

2. U.S Detail Specification. MIL-DTL-32332 (2009)

3. U.S Detail Specification. MIL-DTL-12560K (2013)

4. J. Prifti, M. Castro, R. Squillacioti, R. Cellitti, DTIC Document (1997)

5. D. Showalter, W. Gooch, M. Burkins, V. Thorn, S. Cimpoeru, R. Barnett, 23rd Int Ballistic Symposium (2007)

6. S. Ryan, H. Li, M. Edgerton, D. Gallardy, S. Cimpoeru. Int J Impact Eng, 94, 60-73 (2016)

7. B. McDonald, H. Bornstein, G. Langdon, R. Curry, A. Daliri, A. Orifici, Int J Impact Eng, 115, 106119 (2018)

8. T. Børvik, O. Hopperstad, T. Berstad, M. Langseth. Eur J Mech - A/Solids, 20, 685-712 (2001)

9. A. Ameri, Z. Quadir, B. McDonald, A. Orifici, J. H. Bornstein, Escobedo-Diaz. DYMAT 2018, (2018)

10. L. Schwer. 6th Eur. LS-DYNA Users' Conf. Frankenthal, Ger, 6, 11-22 (2007)

11. M. Cockcroft, D. Latham. J Inst Met, 96, 33-9 (1968)

12. T. Børvik, S. Dey, A. Clausen. Int J Impact Eng, 36, 948-64 (2009)

13. V. Aune, G. Valsamos, F. Casadei, M. Larcher, M. Langseth, T. Børvik. Int J Impact Eng, 99, 131-144 (2017)

14. M. Buyuk, PhD Thesis, George Washington University (2014)

15. J. Lambert, G. Jonas, Ballistic Research Laboratories (1976) 